\title{
Nursing home residents used 6 strategies to manage urinary incontinence
}

Robinson JP. Managing urinary incontinence in the nursing home: residents' perspectives. J Adv Nurs 2000 Jan;31:68-77.

\author{
QUESTION: How do residents of nursing homes experience living with urinary \\ incontinence (UI)?
}

\author{
Design \\ Grounded theory.
}

Setting

3 nursing homes in the metropolitan area of a large, US city.

\section{Participants} range 69-93 y, 80\% white) who were cognitively intact, spoke English, and acknowledged actual or potential UI related to symptoms of frequency or urgency. Most required moderate to extensive assistance with toileting, had urine leakage, and wore some type of absorbent product. 33 secondary participants $(82 \%$ women) also showed evidence of actual or potential UI and were encountered during recruitment excursions, formal interviews, or follow up visits to primary participants.

\section{Methods}

Primary participants provided an indepth interview, subsequent opportunities to observe and discuss their methods of bladder control, and access to their healthcare records. Secondary participants were observed and interviewed informally as bladder control issues arose. Theoretical saturation occurred after 30 encounters with primary participants and 34 encounters with secondary participants. Minutes of resident advisory council meetings were also reviewed. Data were analysed using the constant comparative method. Findings were validated by 5 study participants and 1 non-participating resident.

\section{Main findings}

Participants engaged in a dynamic process called "managing UI," whereby they used 6 strategies. Limiting strategies included self imposed restrictions on activities and behaviours (eg, limiting fluid intake). Improvising referred to discovering or inventing methods to accomplish voiding, prevent accidents, and accommodate leakage. Learning involved acquiring information or skills to prevent or manage leakage (eg, details of bathroom accessibility and transfer skills). Monitoring referred to attending to attributes of the environment (eg, nursing home routine), care (eg, outcomes such as skin condition and comfort), and bodily function (daily input and output) to manage leakage. Speaking up involved communicating needs, opinions, and ideas about UI management to physicians, caregivers, and visitors. Letting it go was the accidental, deliberate, or negotiated urination in other than a standard receptacle (eg, deliberately choosing to wet oneself). The consequences of managing UI ranged from "making the best of it" to "suffering with it." When strategies were used by residents, supported by others, and provided satisfaction to the resident, conditions favoured "making the best of
Primary participants were 6 women and 4 men (age

it"; when strategies were used minimally, not supported, and provided little or no satisfaction to the resident, "suffering with it" was the likely consequence.

\section{Conclusions}

Nursing home residents managed potential or actual urinary incontinence within the context of a belief that incontinence was an inevitable part of aging and with the goal of protecting their physical, psychological, and social integrity. The consequences of managing UI were largely determined by the degree to which residents used 6 management strategies and were satisfied with them, and the degree to which others supported these strategies.

\section{COMMENTARY}

At least $50 \%$ of nursing home residents experience UI, ${ }^{12}$ and yet, few studies have examined how the condition affects this client population. The study by Robinson goes some way to addressing this knowledge gap within the context of 3 nursing homes in a US city. The full range of perspectives of nursing home residents may not be represented by the participants in this study; for example, the experiences of residents belonging to ethnic minorities or those who are severely distressed by UI may differ. Community studies of non-institutionalised people confirm that the elderly see UI as an inevitable part of aging, and that they manage UI using a range of strategies to preserve their physical, psychological, and social wellbeing. ${ }^{3}$

This study provides nurses and other practitioners with useful insights into how care may be improved in these clients. Understanding the range of residents' self management strategies and more importantly, the underlying reasons for their adoption, can help to identify the barriers and supports to providing effective continence care in nursing home settings. Residents' misconceptions about the inevitability of UI may lead to behaviour that focuses exclusively on symptom control rather than continence promotion. Staff may also be unwilling to implement effective continence measures if residents' low expectations make them reluctant to collaborate in their treatment programmes.

Educational interventions that target nursing home residents and their families, and are supplemented by wider, population based public health messages, will help to dispel some of the myths that still surround UI in elderly people. More work is needed, however, to establish which educational methods are most effective in this population. Francine M Cheater, RGN, PhD Senior Lecturer (Nursing) University of Leicester Leicester, $U K$ DrJ P Robinson, The State University of New Jersey, College of Nursing 180 University Avenue, Newark, NJ 07102, USA. Fax +19735351277 .
1 Brandeis GH, Baumann MM, Hossain M, et al. J Am Geriatr Soc 1997;45:179-84.

2 Sgadari A, Topinkova E, Bjornson J, et al. Age Ageing 1997;26(suppl 2):49-54

Mitteness LS. Res Sociol Health Care 1987;6:177-219.

4 Dowd TT. Res Nurs Health 1991;14:179-86. 